\title{
Entrevista a Rosario Ricaldi, feminista y exmiembro de la Asamblea Constituyente de Bolivia (2006)
}

\author{
Claudia Iriarte Rivas \\ Universidad de Chile
}

\section{Introducción}

El actual proceso constituyente es un hecho inédito en la historia reciente de Chile. Sin embargo, diversos países de América Latina ya han vivido sus propios procesos de cambio constitucional, los que no han estado exentos de desafíos. Conocer sus experiencias y la forma en que lograron construir sus cartas fundamentales nos permitirá anticiparnos a debates que, a medida que avance el proceso, comenzarán a surgir.

Uno de esos países es Bolivia, que en el año 2006 inició una Asamblea Constituyente que culminó el 2009 con la promulgación de Constitución Política del Estado Plurinacional de Bolivia. En atención a ello, en esta oportunidad conversamos con Rosario Ricaldi, feminista y exmiembro de la Asamblea Constituyente de Bolivia.

¿Cuáles considera usted que son los antecedentes del proceso constituyente boliviano y de la definición de una asamblea constituyente como mecanismo de deliberación?

Las exclusiones históricas de indígenas, mujeres y campesinos de la toma de decisiones y del aprovechamiento de los recursos fueron los antecedentes directos de la Asamblea Constituyente. Estas situaciones socavaron a tal punto la estabilidad que desde el año 2000 se agudizaron las movilizaciones sociales que venían desde, al menos, los años noventa. Durante esta década, los pueblos indígenas, al verse absolutamente invisibilizados en el Estado y no recibir nada de él, desarrollaron un proceso de visibilización de su agenda en torno a tres pilares: soberanía, territorio y dignidad. Esta agenda fue la que pusieron sobre la mesa y resultó ser un antecedente a la propuesta que ellos hicieron de una asamblea constituyente como el hecho político de reencuentro y de visibilización de los sujetos históricamente excluidos. 
Otro de los hitos que precedió a la Asamblea Constituyente ocurrió en el 2000, cuando surgieron movilizaciones en las ciudades producto del rechazo de la privatización del agua. La denominada "guerra del agua» tuvo como detonante la privatización hecha durante el Gobierno de Gonzalo Sánchez de Lozada (2002-2003) de los recursos hídricos, lo que desencadenó la movilización de los sectores populares de Cochabamba, donde el pueblo, de forma impresionante, se levantó frente a esta situación.

En este momento ya se evidenciaba la hegemonía neoliberal que privilegiaba a pocos y nos hundía a muchos. En ese sentido, en el 2002 se dieron las elecciones generales y Evo Morales y el MIR (Movimiento de Izquierda Revolucionaria), dos fuerzas emergentes que visibilizaban y denunciaban los efectos del modelo neoliberal, lograron una buena bancada.

Luego, en el 2003, se dio la "guerra del gas» en El Alto, otro hito precedente de la Asamblea Constituyente. Este conflicto logró movilizar a todo el país, lo que generó un proceso fuerte de debate respecto de los recursos de hidrocarburos, con dos posiciones respecto de cómo explotar estos recursos: una buscaba favorecer a las transnacionales y otra buscaba su nacionalización.

Esos debates nos llevaron a confrontarnos en el denominado «febrero negro», en la guerra del gas, que llevó a la destitución del presidente Sánchez de Lozada y su huida del país. En este periodo tomó el poder el vicepresidente Carlos Meza, al mismo tiempo que se fue articulando el movimiento popular en lo que luego pasó a llamarse el «Pacto de Unidad», que articuló a sectores estratégicos como la Central Obrera Boliviana, la Confederación de Trabajadores Rurales de Bolivia (CSUTCB), la Confederación de Pueblos Indígenas de Bolivia (CIDOB), los colonizadores de Bolivia, el Consejo Nacional de Ayllus y Markas del Qullasuyu y la Federación Departamental de Mujeres Campesinas Bartolina Sisa.

En la situación de crisis que vivía el país, surgió con fuerza la idea de la necesidad de la descentralización, porque regiones como Tarija, Beni, Santa Cruz y Pando demandaban la autonomía, exigencia que, si bien no estaba bien posicionada en la agenda nacional, sí era un interés regional. Estos territorios corresponden a regiones ricas, que lamentablemente se encontraban postergadas, sin tener beneficios de los bienes del Estado - con excepción de Santa Cruz-, dándose la articulación de lo que posteriormente llamamos «la media luna», que posicionó la demanda de la autonomía e incluso el federalismo.

A partir de estos hechos, en febrero de 2004 se produjo una reforma a la Constitución en que se incorporaron algunos mecanismos, dentro de los cuales se encuentran la posibilidad de una convocatoria a una asamblea constituyente, el referéndum constitucional, la iniciativa legislativa popular y la desmonopolización de los partidos políticos de la política. 
En este periodo se dio una crisis muy fuerte en el país, a partir de la cual se convocaron a múltiples cabildos. En el 2004, después de la agenda de enero, surgió la agenda de octubre, la que se convirtió en la bandera de lucha de los movimientos sociales en el país y que terminó por enarbolar la bandera de la Asamblea Constituyente. Luego, en el 2005, tras el proceso eleccionario, ganó Evo Morales con el 53,7\% de los votos, portando como uno de sus compromisos cumplir la agenda de octubre. A partir de ello, se logró una importantísima participación en la Cámara de Diputados y de Senadores, como antes no se había tenido. La izquierda nunca había tenido tanta presencia en el Gobierno como esa vez, fue algo histórico.

En este proceso se dio un pacto que imponía la necesidad de dos tercios en el cuórum del Congreso Constituyente - a estas alturas todavía no se hablaba de Asamblea Constituyente- - Este cuórum se fijó con el fin de aprobar lo que sería la convocatoria a la Asamblea Constituyente. El 6 de marzo de 2006 se promulgó la Ley de Convocatoria a una Asamblea Constituyente de forma paralela al referéndum de autonomía. Esa fue la fórmula que se encontró para atender las dos agendas y dar el gusto a las dos poblaciones, porque, si no, el conflicto no terminaba. Entonces, el 2 de julio de 2006 se celebraron las elecciones y, de los 255 escaños, 130 fueron conseguidos por el Movimiento al Socialismo (MAS), 88 mujeres, entre ellas yo, que fui invitada por el MAS a ser candidata a la Constituyente como representante de la lucha de las mujeres.

Por último, el 6 de agosto de 2006 se instaló la Asamblea Constituyente, continuando un proceso que había sido tenso desde el inicio. El proceso de elecciones fue duro, bastante violento y confrontado, ya que las visiones de país eran evidentemente contrapuestas. Así, mientras unos aspiraban a una Bolivia casi federalista, otros aspirábamos a recuperar la propiedad de nuestro país, ya que lo sentíamos por completo enajenado. Ambas visiones de país se posicionaban en el proceso constituyente con mucha fuerza, con mucha confrontación y con bases sociales que desde ambos lados se movilizaban. Nosotros también apostábamos por la autonomía, pero no una autonomía como la planteada por ellos, que nacía de la condición de privilegios que tenían. En este ambiente se dio la Asamblea Constituyente.

Durante la Asamblea, el primer gran tropiezo que tuvimos fue el reglamento de debates. En la Ley de Convocatoria a la Asamblea Constituyente nos decían que nosotros debíamos regirnos por un título de la Ley de Reglamento de debates del Congreso, hasta que nosotros conformáramos nuestra organización interna y nos diéramos un reglamento propio, como así lo hicimos.

Sin embargo, cuando queríamos aprobar nuestro Reglamento de debates, el tema que generó el mayor quiebre fue el sistema de votación para aprobar la Constitución y el carácter de la asamblea, es decir, si era originaria o derivada. El 29 de septiembre recién se aprobó el primer artículo del reglamento de debates, declarando que nues- 
tra asamblea era originaria. Nosotros planteábamos nuestra asamblea como originaria porque sentíamos que era necesario dar nacimiento a una nueva Bolivia que nos incluyera a los que históricamente hemos estado excluidos, rescatando aquello que los pueblos indígenas habían hecho evidente: eran ciudadanos que guardaban todo el patrimonio natural de este país, pero al mismo tiempo estaban invisibilizados y no gozaban de ningún derecho. Entonces, para nosotros, una forma de honrar aquella lucha era definir a la asamblea constituyente como originaria y, con eso, dar nacimiento a un nuevo Estado que nos incluyera a todos.

Esta definición generó mucho debate al interior de la propia Asamblea, en los medios de comunicación, en las organizaciones y en la sociedad boliviana. Este debate al interior de la Asamblea se manifestó en la decisión sobre los cuórums que se requerían para lograr los acuerdos de la nueva constitución. El Pacto de Unidad y el MAS defendíamos la mayoría absoluta para la aprobación, asumiendo una posición radical, porque no dimos lugar a la negociación. Nuestra posición era mayoría para aprobar, porque lo veíamos como justo. Nosotros representábamos a más de la mayoría, pero la oposición tenía la habilidad de visibilizarse, a pesar de ser una minoría, porque tenía el poder de los medios de comunicación, haciendo ver que nosotros estábamos «imponiendo» e «invisibilizando» esta otra posición. Han tenido un manejo de medios muy fuerte, yo diría que los medios han jugado un rol estratégico de resistencia a las transformaciones.

Podemos, que era la fuerza opositora dentro de la Constituyente, planteaba la idea de los dos tercios en la discusión sobre el cuórum de votación, mientras nosotros nos cerrábamos con la mayoría absoluta. Al interior del MAS, nuestro directorio ad hoc hizo un ejercicio de consenso dentro de las bancadas de los constituyentes y tuvimos unas reuniones de cada departamento para ver cómo podíamos destrabar esta situación. A pesar de ello, había una posición clara en todas las bancadas (siete de nueve), las cuales decíamos que aprobaríamos la mayoría de la Constitución por mayoría absoluta, y los temas más duros que necesitan negociación los aprobaríamos por dos tercios, en el afán de lograr consensos. Lo íbamos a hacer, pero la mirada estratégica del presidente en ese momento nos hacía ver que eso no iba a viabilizar nuestra constituyente, sino que la iba a empantanar, porque preveía la posición de la oposición. Preveía la crisis que se iba a venir. Teníamos nosotros una gran desventaja, porque si bien estábamos fuertes por dentro, por el respaldo que tenía Evo Morales y el Gobierno, teníamos todo un entorno desfavorable, tanto de actores, recursos y medios de comunicación en contra. Todavía no estábamos en condiciones de poder para imponer esa mayoría. Sin embargo, fue visionaria esa posición.

A la larga, nosotros vimos que en la Asamblea Constituyente no había ninguna posibilidad de que la oposición cediera en sus ideas o buscara consensos, así que la oposición no escribió un sólo artículo de la Constitución, manteniendo como actitud permanente el boicot del proceso. Finalmente, se logró una salida de la siguiente ma- 
nera: se decidió que los informes de comisión y la primera votación, en general, sería por mayoría absoluta y el tratamiento en detalle sería por dos tercios. A ese nivel de acuerdo se llegó. Se dijo además que, en caso de no existir aprobación por dos tercios, la divergencia pasaría a consulta popular, para que la población decida por voto, y así saldría el proyecto final.

Mientras se desarrollaba la Asamblea Constituyente, en Sucre se generó una tensión impresionante porque la oposición, que buscaba boicotear el proceso, revivió la antigua discusión sobre qué ciudad debía ser la capital de Bolivia, un tema que venía siendo motivo de contienda histórica desde 1898 . Se posicionó el tema de «Sucre capital», en torno al cual se articuló no sólo a la media luna, sino que también a la gente de Sucre, lo que generó una exacerbación de los ánimos sucrenses y generó un clima de permanente movilización en torno al funcionamiento de las 21 comisiones de la Asamblea Constituyente, protestando y exigiendo que se apruebe que la sede sea Sucre. Esto era imposible, porque toda la institucionalidad y la infraestructura del poder está en La Paz, por lo que hacer este cambio era inviable. En ese sentido, se ha utilizado a la población para hacer de Sucre un lugar de contienda, de resistencia, y la gente se dejó llevar, porque también tenemos en Sucre una población racista, que quedó en evidencia durante el proceso constituyente. Tanto fue el racismo durante el proceso que, por ejemplo, a constituyentes de polleras que pretendían alojarse en hoteles cinco estrellas - donde se realizaban eventos de la Asamblea Constituyente y donde nos reservaban lugar a todos- no las dejaba alojarse porque eran cholas, las sacaban de sus casas, no les querían alquilar. En la calle, las escupían a nuestras compañeras indígenas. Ese grado de racismo hemos vivido en Bolivia.

Yo creo que hemos vivido un momento tan duro, de tanto odio, que a mí todavía me impacta. Porque lo que ha vivido Bolivia el año pasado, con las muertes, muestra cómo todavía esta derecha racista no acepta nuestra verdadera identidad. Es impresionante leer, ver... Me quiebra, siempre me quiebra. Ha sido un periodo muy duro para nosotros, muy duro.

Usted nos señaló que pasó un mes y medio hasta que lograron tener los primeros elementos del Reglamento, pero después pasaron meses trabajando en un clima altamente conflictivo. ¿Cuánto duró ese período tan complejo de debate hasta que fueron avanzando en la Constitución?

Todo el 2006. En agosto del 2006 se instaló la Asamblea Constituyente y en septiembre aprobamos el primer artículo, iniciándose las confrontaciones y hechos de violencia que impedían el funcionamiento. A pesar de eso, se siguió trabajando en comisiones.

Luego, a fines de 2006, cuando se intentó la aprobación de la Constitución, se dio una ofensiva muy fuerte de los opositores. Por ejemplo, el 23 de noviembre hubo un 
desalojo a los constituyentes con el objeto de no dejarnos sesionar. Ante ello, debimos cambiar de lugares y funcionar en la clandestinidad. Nos instalamos en el Liceo Militar de la Glorieta para hacer la aprobación de la Constitución.

En la Asamblea ya se habían trabajado 470 artículos de la Constitución, pero no había existido un periodo de diálogo entre todas las comisiones que diera coherencia y lograra integrar lo trabajado. Ese trabajo en conjunto se llevó a cabo en la Casa Argandoña durante tres días completos. En ese lugar, yo tenía el libro De la protesta al mandato: Una propuesta en construcción, que era mi mandato. Yo veía ahí mujeres campesinas, cocaleras, medioambientalistas, las compañeras con las que trabajábamos, y tenían un pedacito de papel guardado en su seno. ¿Qué era eso? Era su mandato. Es que ahí teníamos a mineras, campesinas, indígenas de todos los sectores y ya tenían redactado su mandato, esto era lo mínimo no negociable, esto sí o sí tenía que entrar.

Entonces, en ese período comprimimos más de 400 artículos. Fue increíble, porque teníamos que ir sacrificando algo de lo que teníamos para lograrlo. Teniendo ya el documento más o menos para ser aprobado, nos fuimos al Liceo Glorieta, en un contexto de conflictividad. En Sucre la población estaba en las calles y quemaba estaciones de policías y oficinas, a este lugar habían llegado los grupos paramilitares que tenía la oposición en Santa Cruz, la Unión Juvenil Cruceñista fue a Sucre y empezó a armar un desbande total, a quemar la ciudad prácticamente. Los asambleístas, por nuestra parte, estábamos encerrados en el Liceo Glorieta, resguardados por los movimientos sociales que se habían venido de La Paz, del Alto, de Oruro, de Potosí, de Tarija, quienes cercando el colegio nos decían: «Vamos a proteger nuestra asamblea. Ustedes aprueben la Constitución, nosotros la vamos a cuidar para impedir que vengan los chuquisaqueños a impedir que nosotros podamos aprobar la Constitución».

Bajo esa presión aprobamos la Constitución, de los 255 constituyentes que estuvimos en las sesiones, sólo participamos 145, los demás o fueron oposición o no se sumaron al proceso. Así, aprobamos la Constitución por mayoría y luego, producto del ataque que sufrió la Asamblea, salimos huyendo prácticamente del Liceo.

Posteriormente nos fuimos a La Paz, estuvimos en comisiones pequeñas trabajando cómo había quedado la aprobación en grande y los temas que quedaban para la aprobación en detalle. Teníamos que aprobar en detalle el Reglamento y ver las condiciones políticas, en qué momento era lo más oportuno y en qué ciudad se daban las condiciones para aquello. De ahí es que los mineros de Oruro nos dicen: «Vénganse a Oruro, nosotros aquí instalamos un lugar de sesión». Nos fuimos a Oruro el 8 de diciembre de 2007.

Aprobamos la Constitución en detalle. Ahí se sumó más gente. Llegamos a ser 153, sumándose 13 constituyentes de la oposición que tenían base social popular y sus bases los obligaron a dar cumplimiento a sus mandatos. Por ejemplo, un constituyente que es cuentapropista (trabajador por cuenta propia) fue obligado por su organiza- 
ción a participar. Luego, el 15 de diciembre, la presidenta de la Asamblea Constituyente entregó el proyecto de la Constitución al presidente Evo Morales y, con ello, la Asamblea Constituyente culminó su proceso. Eso fue el 15 de diciembre de 2007.

Se trabajó durante un año y tres meses, para ello se tuvo que aprobar una ley ampliatoria que permitiera a la constituyente seguir trabajando. La imposibilidad de aprobar el Reglamento nos demandó cerca de medio año de debate.

Mientras funcionaba la Asamblea Constituyente, ¿cómo era el funcionamiento del Congreso?

El Congreso continuó en funcionamiento, aprobando leyes. Cada órgano mantuvo su rol intentando que no hubiera ninguna injerencia.

Sin embargo, aprobada la Constitución en Oruro, no podíamos llevarla a referéndum, dada la convulsión social y la resistencia de quienes la consideraban la «Constitución del MAS». Ese discurso se abstraía totalmente de la realidad, que era que nosotros éramos representantes de más del $50 \%$ de la población.

Lo antes señalado llevó a una salida que afectó el carácter originario de nuestra asamblea. Se tuvo que llegar a una negociación dentro del Congreso, donde se formó una comisión entre las fuerzas que tenían más representación. Con el objeto de contribuir a este diálogo, se generaron los espacios de negociación y de articulación, celebrando en Cochabamba comisiones de negociación, que implicaron sacrificar algunos artículos de la Constitución.

En el referéndum, que ganamos con un muy importante respaldo, el $61 \%$ de la población apoyó la nueva Constitución.

¿Qué destacaría, en lo que se refiere a la profundización democrática, del proyecto constitucional que finalmente aprobaron y que está hoy día vigente como Constitución? ¿Cuáles son los aspectos más sustanciales del texto constitucional que elaboraron?

Yo diría que el artículo 1, sobre cómo nos constituimos. Esta disposición resume lo que ha implicado esta Constitución. A pesar de la resistencia de la oposición a reconocer que somos un Estado plurinacional, el artículo 1 dice:

Bolivia se constituye en un Estado unitario, social de derecho, plurinacional, comunitario, libre, independiente, soberano, democrático, intercultural, descentralizado, con autonomías y nos fundamos en esta pluralidad como pluralismo político, económico, social, cultural, lingüístico dentro de este proceso integrador de país.

Cuando hablamos de esta pluralidad, hablamos, por ejemplo, del pluralismo económico. La oposición decía que nosotros estamos en contra de la propiedad privada, lo que no es correcto, aquí se respeta la propiedad privada, se respeta la propiedad del Estado y se respeta la propiedad cooperativa. Hay un pluralismo económico que se 
reconoce, sobre el que el Estado se construye. También hablamos del pluralismo jurídico, que reconoce la existencia de pueblos indígenas y de una justicia indígena que se administra en sus pueblos. Se reconoce la democracia plural, que es la esencia del proceso constituyente y por la que más de 20.000 mujeres en toda Bolivia se movilizaron, ya que nuestra propuesta se construyó desde nuestra diversidad: campesinas, indígenas, mineras, cafetaleras, de todos los rincones del país.

Todo este debate delicioso, riquísimo, que hemos vivido en el proceso preconstituyente no hemos podido disfrutarlo a plenitud durante el proceso constituyente propiamente tal, por el trabajo a presión y la imposibilidad de que fueran debates públicos y educativos.

Sin embargo, yo diría que el esfuerzo que ha hecho la Constituyente de hacer encuentros territoriales en cada departamento, en que las 21 comisiones recibían en audiencia a la gente, se incorporaban las propuestas de lo que la gente planteaba y se informaba el estado de los debates, ha sido un proceso educativo muy importante para Bolivia.

La Constitución la encontrabas con total normalidad en la gente que vende los mercados, todos tienen su Constitución en la bolsa, todos saben lo que está escrito aquí. Eso, me parece que, para cualquier proceso constituyente, es un logro en el empoderamiento ciudadano.

Además, me parece importante y estratégico que la Constitución mande a que el pueblo es el dueño de los recursos naturales, recordando que los temas que han provocado la Constituyente han sido la guerra del agua, la guerra del gas y en definitiva el control sobre los recursos naturales, que en Bolivia había sido siempre dependiente de las élites.

A partir de esta Constitución, cambian los sistemas de elección de los miembros de algunos órganos. Ya no es Poder Ejecutivo, el Poder Judicial o el Poder Electoral los que administran la decisión. A partir de la Constitución, son elegidos por el voto de la población o por sus representantes que han sido elegidos por voto.

El grado de democracia al que nos lleva nuestra Constitución es alto. Es interesante, por ejemplo, que la Constitución dice que sobre los recursos naturales debe decidir el soberano. Así, un contrato sobre litio no lo puede decidir la Asamblea Legislativa plurinacional, debe ser aprobado por el soberano, mediante consulta.

Este alto grado de democracia requiere que la población se empodere, se politice y tenga dominio de su Constitución. Yo creo que Bolivia ya ha logrado un interesante grado de ello, por eso estamos en la situación actual, con un Gobierno que se ha ratificado, a pesar de una resistencia que hemos tenido por meses en el poder y que representa el $4 \%$ del voto del pueblo, encabezada por la figura de Jeanine Añez. El pueblo fuerte ha logrado reposicionar su proyecto de país. Siento que ahí está la riqueza de la legitimidad de la Constitución, así como la legitimidad del proyecto político.

Otro punto interesante de la Constitución es que los tratados internacionales que 
Bolivia ratifique en materia de derechos humanos deban ser reconocidos en la Carta Fundamental y en la pirámide normativa como ley inmediatamente luego de su ratificación. Ello representa un gran avance y una gran ganancia para quienes defendemos y luchamos por los derechos humanos.

¿Cómo se reflejan los temas de género en el proceso constituyente boliviano? ¿Algunas de las propuestas presentadas por las mujeres fueron recogidas en la Constitución?

Les recomiendo ver el video del Observatorio de Género de Bolivia de la Coordinadora de la Mujer, que se llama «Mujeres presentes en la historia». En él, 41 mujeres resumen el proceso. Allí se representa esa pluralidad riquísima de mujeres que hemos estado trabajando de la propuesta al mandato, que es una propuesta en construcción. Todos los derechos que hemos planteado han sido incorporados en la Constitución, excepto el derecho al aborto, que no ha entrado porque era un debate muy fuerte que teníamos frente a una Sucre tan resistente, tan colonial, tan conservadora. Este tema nos estaba poniendo en riesgo los derechos sexuales y reproductivos.

Se ganó el derecho a la vida y los derechos sexuales y reproductivos como derechos específicos de las mujeres, además de otros, como el derecho a vivir libre de violencia, el derecho a que nuestra maternidad sea segura, el derecho a democratizar los roles del trabajo, del hogar, tema en el que hasta hoy existen debates, la distribución de roles como derecho y obligación. El derecho a que nosotras decidamos el tiempo de registrar a nuestros hijos y quién es el padre, y no esa duda que siempre nos han dejado por tener maternidad sola. Antes, nosotras no teníamos la posibilidad de darle el apellido a nuestro hijo porque el marido no aceptaba la paternidad, pero a partir de esta Constitución, nosotras decidimos éste es el padre y lo registramos; además, se reconoce la obligación del padre de asumir la manutención de los hijos.

También se reconoce a las mujeres el derecho a acceder a la titularidad de la tierra, el derecho al igual salario por igual trabajo, el derecho al reconocimiento del aporte económico de las mujeres en la economía del Estado.

La participación paritaria fue cuestionada por muchas feministas en Bolivia, pero cuando nosotros hacemos un seguimiento a los logros de la paridad, nos damos cuenta de que si no hubiesen estado las mujeres en los espacios de decisión constituyente, muchos logros dentro de la Asamblea Constituyente no se habrían alcanzado; se ve cuán valioso es y cuánta diferencia hace tener mujeres en espacios de decisión: se comprometen, se involucran, aportan, asumen responsabilidad, creo que mucho más que los hombres. Parece antipática la comparación, pero no sólo yo veo eso. Estar en el poder marca la diferencia, la paridad es absolutamente estratégica para generar cimientos de cambios en los sistemas patriarcales, coloniales, que tenemos. Creo con seguridad que estamos dando pasos importantes con esta participación paritaria y democrática. 
Nosotros enfrentamos ahora un proceso constituyente con una realidad posiblemente distinta a la de ustedes, porque este país tiene una formalidad que le pesa, pero hay debates de lo que tú has comentado hoy que obviamente van a estar presentes desde ahora, incluso respecto de cómo se eligen a los constituyentes, el tema del reglamento también. ¿Qué destacarías del proceso constituyente boliviano pensando en una realidad como la chilena? ¿Respecto de qué situaciones hay que tener mayor preparación? ¿Qué sienten ustedes que es sustancial tener presente o a qué se debe estar alerta en procesos constituyentes de los países de América Latina?

Yo creo que el proceso chileno se parece al nuestro en toda la convulsión previa que se ha generado, en toda la aspiración de ese pueblo que ha ido a votar con tanta expectativa por una salida constituyente. Pensando en esto, creo que, si nosotros hubiésemos tenido una estrategia de negociación desde el inicio de la Asamblea Constituyente para discutir el reglamento, con mayor habilidad de negociación y encontrando desde el principio los puntos de acuerdo, quizás no hubiésemos perdido tanto tiempo y no hubiésemos dejado que se polaricen tanto las cosas. Quizás no hubiésemos dado chance para que la oposición se arme de manera tan violenta como lo ha hecho. Esas estrategias de tener actores del diálogo, de la diplomacia, del acuerdo, son esfuerzos necesarios de hacer, a pesar de que exista mucha sangre de por medio, mucha historia y aspiraciones diferentes.

Creo que la academia puede jugar un rol fundamental en ser un puente de diálogo, de diplomacia, de democratización; creo que es muy importante dotarse de un equipo técnico plural, amplio, técnicamente abierto, que pueda ver más allá del tecnicismo constitucional, que a veces nos ciega y no deja escuchar.

En cuanto a normar el funcionamiento de la Asamblea Constituyente, a mí me parece que hay que pensar los temas sobre los que tienes que comprometer a los candidatos. Para que ya cuando candidatos esté asegurado que cuando estén en sus funciones, cumplan desde el inicio los acuerdos de la reglamentación de funcionamiento de la Asamblea. Creo que éstos podrían ir acordados antes, comprometiendo a los que puedan ser constituyentes.

Para generar una tendencia que ayude a pensar en Chile, es necesario pensar en el proyecto país para todo el pueblo antes que para algunos grupos. En Bolivia, la oposición ha logrado esto de la bolivianidad, del símbolo de lo que te refleja, a pesar de que yo sé que lo hacen con intereses mezquinos, económicos. Nosotros no hemos sabido trabajar eso mediáticamente, no hemos sabido desenvolvernos mejor en los medios, a pesar de tener los medios del Estado. Yo creo que hay que hacer un buen uso de esa comunicación para que ayude al diálogo, ayude a los acuerdos.

Creo que, en el caso de Chile, hay que trabajar de forma paralela un proceso de reencuentro, hacer que esto sea una oportunidad de sanar heridas. El reencuentro debe ser un tema de la agenda, que creo que puede ayudar a ver los elementos que 
puedan encender las alertas al momento del debate y permitan bajar las tensiones y lograr acuerdos que construyan.

También considero que hay que conseguir compromiso de los candidatos para pactar. En Bolivia nos ha ido bien cuando hemos visto a toda la población debatiendo, a mí me ha sorprendido ver a los niños trabajadores pidiendo que no se prohíba el trabajo de los niños, ellos decían que se iba a hacer clandestino, que los iban a explotar, que mantienen a sus hermanos, a su familia. Este tipo de debates que a veces no anticipas porque vas con una idea de cómo debe ser la Constitución. La realidad te confronta y solamente lo hace cuando das oportunidad a todos de expresarse. A mí me parece eso fundamental, que todos los sectores puedan ser constituyentes, que todos tengan la oportunidad de hacer llegar su mensaje. Tenemos un contexto en que los medios de comunicación presentan muchas rutas, redes sociales, los encuentros presenciales, debates; siento que hay un mundo de oportunidad para comunicarse y recoger esto. Sentir que todos aportan al proceso de hacer un nuevo Chile, lo que es muy rico y legitimador del resultado del proceso.

\section{Sobre la autora}

Claudia Iriarte Rivas es abogada. Doctora en Derecho, investigadora del Centro de Derechos Humanos de la Facultad de Derecho. Actualmente se desempeña como editora del Anuario de Derechos Humanos. Su correo electrónico es ciriarter@derecho.uchile.cl. (D) https://orcid.org/0000-0003-0449-926X. 
El Anuario de Derechos Humanos es una publicación semestral de referencia y consulta en materia de derechos humanos y campos afines. Busca ser un espacio de discusión de los temas centrales en el ámbito nacional e internacional sobre derechos humanos. Es publicado desde 2005 por el Centro de Derechos Humanos de la Facultad de Derecho de la Universidad de Chile.

\author{
EDITORA \\ Claudia Iriarte Rivas \\ ciriarter@derecho.uchile.cl \\ SITIO WEB \\ anuariocdh.uchile.cl \\ CORREO ELECTRÓNICO \\ anuario-cdh@derecho.uchile.cl \\ LICENCIA DE ESTE ARTÍCULO \\ Creative Commons Atribución Compartir Igual 4.o Internacional
}

\author{
\% \\ La edición de textos, el diseño editorial \\ y la conversión a formatos electrónicos de este artículo \\ estuvieron a cargo de Tipográfica \\ (www.tipografica.io)
}

